\title{
Mixing height determination by ceilometer
}

\author{
N. Eresmaa ${ }^{1}$, A. Karppinen ${ }^{1}$, S. M. Joffre ${ }^{1}$, J. Räsänen ${ }^{2}$, and H. Talvitie ${ }^{2}$ \\ ${ }^{1}$ Finnish Meteorological Institute, Research and Development, P.O.B. 503, FI-00101 Helsinki, Finland \\ ${ }^{2}$ Vaisala Oyj, P.O.B. 26, FI-00421 Helsinki, Finland
}

Received: 30 September 2005 - Published in Atmos. Chem. Phys. Discuss.: 9 December 2005

Revised: 6 march 2006 - Accepted: 13 March 2006 - Published: 8 May 2006

\begin{abstract}
A novel method for estimating the mixing height based on ceilometer measurements is described and tested against commonly used methods for determining mixing height. In this method an idealised backscatter profile is fitted to the observed backscatter profile. The mixing height is one of the idealised backscatter profile parameters.

An extensive amount of ceilometer data and vertical soundings data from the Helsinki area in 2002 is utilized to test the applicability of the ceilometer for mixing height determination. The results, including 71 convective and 38 stable cases, show that in clear sky conditions the mixing heights determined from ceilometer based aerosol profiles and BL-height estimates based on sounding data are in a good agreement. Rejected outlier cases corresponded to very low aerosol concentrations in the mixed layer leading to a very weak aerosol backscatter signal in the lowest layer.
\end{abstract}

\section{Introduction}

The planetary boundary layer (PBL) is the layer where the earth's surface interacts with the large scale atmospheric flow. Since substances emitted into this layer disperse gradually horizontally and vertically through the action of turbulence, and become completely mixed if sufficient time is given and sinks and sources are absent, this layer is also called the mixing layer (Seibert et al., 1998).

The PBL height or mixing height (MH) is a key parameter in air pollution models determining the volume available for pollutants to dispersion (Seibert et al., 2000) and the structure of turbulence in the boundary layer (Hashmonay et al., 1991). In spite of its importance there is no direct method available to determine the MH. The most common methods for determining the $\mathrm{MH}$ are utilisation of radiosound-

Correspondence to: A. Karppinen

(ari.karppinen@fmi.fi) ings, remote sounding systems and parameterization methods. All these methods have advantages and disadvantages and consider different related or assumed properties of the PBL. Thus, it is relevant to develop and evaluate new techniques or methods in order to lower the inherent uncertainty involved in the determination of the MH.

Among novel remote sensing methods, a promising one is the ceilometer, based on the lidar-technique, which measures the aerosol concentration profile. Since in general aerosol concentrations are lower in the free atmosphere than in the mixing layer where most sources of aerosols are located, it can be expected that MH is associated with a strong gradient in the vertical back-scattering profile.

Other remote sensing techniques include sodar, radio acoustic sounding system (RASS) and wind profiler. Signals emitted by a sodar are scattered by temperature inhomegeneities characterized by the structure parameter of the acoustic refractive index. According to the observations the backscattered signal $S$ has a secondary maximum at the top of the mixing layer (Beyrich, 1995, 1997). Emeis and Türk (2004) detected the MH from the sodar data employing two different criteria. According the first criterion a sharp decrease of the acoustic backscatter intensity indicates the top of the turbulent layer; the second criterion diagnoses the (secondary) maxima of the backscatter profile. The search is done separately with both criteria, and the lower height is chosen to denote the MH.

The mixing height can be determined by a wind profiler from the signal-to-noise ratio (SNR). The return signal is received primarily from the inhomogeneities of the radio refractive index (Angevine et al., 1994). These inhomogeneities depend primarily on the fluctuations of the temperature and especially the moisture fields (White et al., 1991). Since there is often a humidity gradient between mixing layer and free atmosphere, a peak can be seen in wind profiler backscatter profile at the top of the mixing layer and SNR (Cohn and Angevine, 2000). However, since the moisture

Published by Copernicus GmbH on behalf of the European Geosciences Union. 
Table 1. Technical properties of the CT25K ceilometer.

\begin{tabular}{ll}
\hline Measurement range & $0-7500 \mathrm{~m}$ \\
Resolution & $15 \mathrm{~m}$ \\
Laser & InGaAs MOCVD laser diode \\
Wave length & $905 \mathrm{~nm}$ \\
Pulse properties & $100 \mathrm{~ns}, 1.6 \mu \mathrm{J} /$ pulse \\
\hline
\end{tabular}

profile is often not as well mixed as temperature profile, there might be some ambiguity in the derived MHs (Seibert et al., 2000)

A RASS detects the speed of a sound wave and thus the profile of the virtual temperature (Görsdorf and Lehman, 2000). Since RASS can also provide the wind profile, the $\mathrm{MH}$ can be determined using the bulk Richardson method.

Our objective in this work was to examine the potential of a ceilometer in determining the mixing height in clear sky conditions. As the reference mixing height we used a $\mathrm{MH}$ determined by radiosoundings, several diagnostic formulae for $\mathrm{MH}$ and the predictions of a meteorological preprocessor model MetPP-FMI.

\section{Data and techniques}

The data used in this work were obtained at the premises of Vaisala Oyj, Vantaa, Finland, during one year period 5 December 2001-10 November 2002.

\subsection{Measurements}

\subsubsection{Ceilometer}

The Vaisala single-lens ceilometer CT25K (Vaisala Oyj, 2002; Emeis et al, 2004) measures the optical backscatter intensity of the air at a wavelength of $905 \mathrm{~nm}$ (near infrared). Its laser diodes are pulsed with a repetition rate of $5.57 \mathrm{kHz}$. The lens has a focal length of $377 \mathrm{~mm}$ and an effective diameter of $145 \mathrm{~mm}$. Laser beam full divergence and field-ofview divergence of the receiver are $1.4 \mathrm{mrad}$ each. Because of the monostatic optical system and the small divergence multiple scattering effects are negligible and the Mie scattering with scattering angles between $179.9^{\circ}$ and $180.1^{\circ}$ is dominant. Additional technical characteristics are given in Table 1.

The CT25K samples the return signal every $100 \mathrm{~ns}$ from 0 to $50 \mu \mathrm{s}$, providing a spatial resolution of $15 \mathrm{~m}$ from the ground up to an altitude of $7500 \mathrm{~m}$ (Vaisala Oyj, 2002). For safety and economic reasons, the laser power used is so low that the noise exceeds the backscattering signal. This can be overcome by summing a large number of return signals, so the desired signal will be multiplied by the number of pulses, whereas the noise, being random, will partially cancel itself.
The degree of cancellation for white (Gaussian) noise equals the square root of the number of samples. However, this processing gain cannot be extended ad infinitum since the environment is constantly changing.

The backscatter intensity depends mainly on the particulate concentrations in the air. As the size of particles varies with their moisture content, the reflectivity is influenced by atmospheric humidity, too. Clouds, fog and precipitation inhibit measurements. The performance of the CT25K ceilometer is sufficient for analysing boundary-layer structures. Compared to more sophisticated LIDAR systems commonly used for these investigations it has several advantages, including the low first range gate, its ability to operate eyesafe and maintenance-free for several years in any climatic environment with just some regular window cleaning, and its comparably low price. Main disadvantage due to the low emitted power is its relatively low maximum range, but for mixing layer studies (mostly below $3 \mathrm{~km}$ ) this does not present a problem.

Raw ceilometer profiles were obtained every $15 \mathrm{~s}$ (integrated over 65536 individual pulses). For this study, the original ceilometer data were averaged over period of $30 \mathrm{~min}$.

\subsubsection{Radiosoundings}

The reference mixing height was determined from the analysis of radiosoundings. Soundings were performed regularly during the observation period, mainly during working hours. The launching site was $100 \mathrm{~m}$ from the ceilometer. However, due to frequent cloudiness at the study site, a large amount of the soundings had to be rejected. The remaining 109 soundings were divided into convective $(\mathrm{N}=71)$ and stable $(\mathrm{N}=38)$ cases. This division was made subjectively based on the temperature and bulk Richardson number profiles. If the potential temperature lapse rate in the lowest $200 \mathrm{~m}$ thick layer and the bulk Richardson number in the lowest $100 \mathrm{~m}$ thick layer were negative the sounding was considered convective, otherwise stable

\subsection{Method for estimating the mixing height from ceilome- ter measurements}

Since in general aerosol concentrations are lower in the free atmosphere than in the mixing layer, the $\mathrm{MH}$ can be associated with a strong gradient in the vertical back-scattering profile. There exist different methods to determine the $\mathrm{MH}$, e.g. the simple threshold method and gradient method. In a simple threshold method the mixing height is reported, when a backscatter signal falls below a fixed threshold value (Münkel and Räsänen, 2004). Melfi et al. (1985) determined the $\mathrm{MH}$ as a height at which the backscatter signal exceeds the clear air signal by a small value.

In the gradient method a minimum of the first derivate of the backscattering profile $d b / d z$ reveals the mixing height (Endlich et al., 1979; Münkel and Räsänen, 2004; Sicard et 


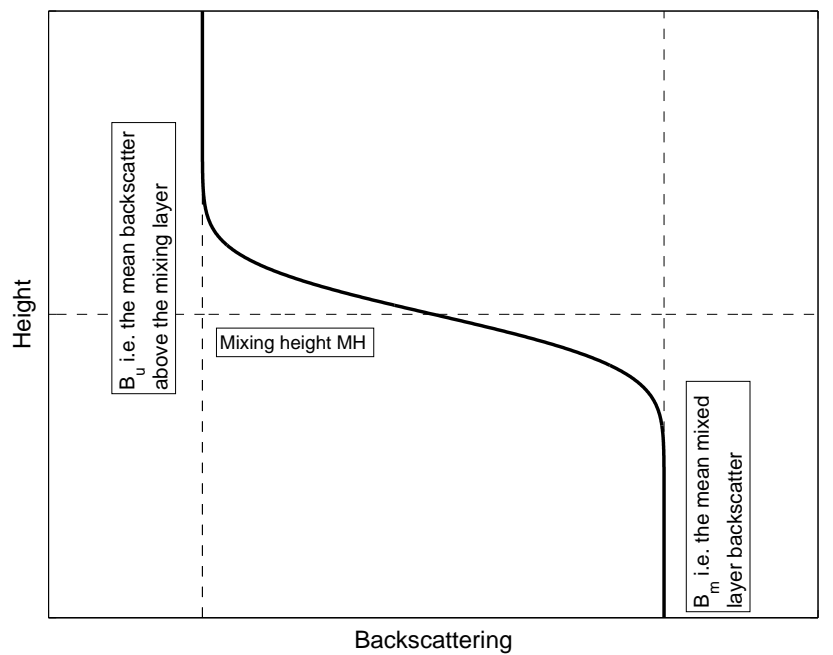

Fig. 1. An idealised backscattering profile.

al., 2004). Also a minimum of the second derivate (Menut et al.,1999; Sicard et al., 2004) or a minimum of the first derivate of logarithm (Sicard et al., 2004), has been used to determine the mixing height.

The method used in this work, originally described by Steyn et al. (1999), is an extension of the gradient method. The mixing height $h$ is not determined from the observed backscatter profile, but from an idealized backscatter profile fitted to the observed profile. The robustness of this technique is in utilizing the whole backscatter profile rather than just the portion surrounding the mixing layer.

In this method an idealized backscattering profile $B(z)$ is fitted to measured profile by the formula

$B(z)=\frac{B_{m}+B_{u}}{2}-\frac{B_{m}-B_{u}}{2} \operatorname{erf}\left(\frac{z-h}{\Delta h}\right)$

where $B_{m}$ is the mean mixing layer backscatter, $B_{u}$ is the mean backscatter in air above the mixing layer and $\Delta h$ is related to the thickness of the entrainment layer capping the PBL in convective conditions.

We define new constants $A 1$ and $A 2$ so that $A 1=\left(B_{m}+B_{u}\right) / 2$ and $A 2=\left(B_{m}-B_{u}\right) / 2$. An idealised profile structure corresponding Eq. (1) is illustrated in Fig. 1. In this idealised case the backscatter above mixing layer and inside mixing layer have constant values $B_{u}$ and $B_{M}$ correspondingly and $\mathrm{MH}$ is defined to be the height of the centre of the entrainment layer.

The fitting procedure was automated with Matlab 6.5 software package (Math Works Inc.). The parameter $A 1$ in Eq. (1) is kept fixed during the fitting. However, the fitting is strongly dependent on the initial values; therefore it is more efficient if these values are chosen according to the initial order-of-magnitude estimate for the mixing height based on stability conditions and the structure of the backscattering profile.

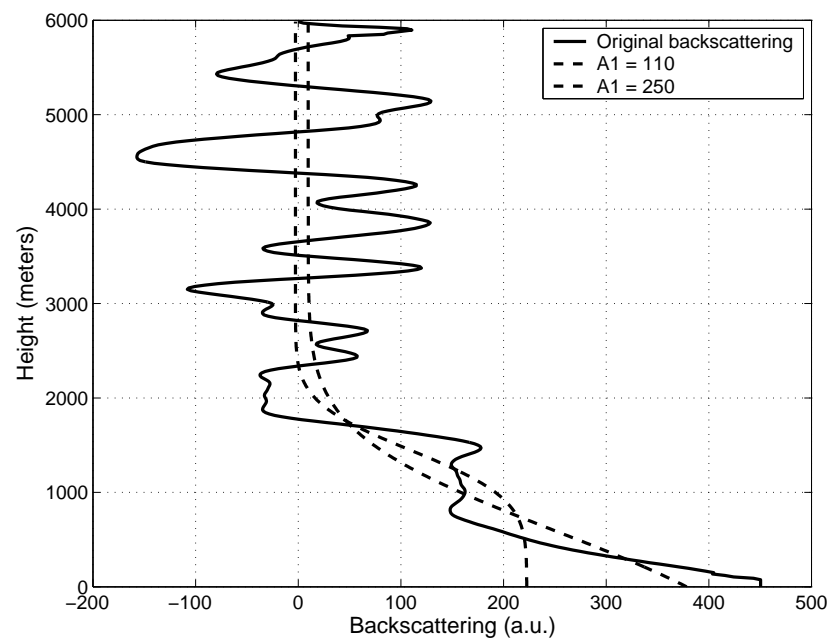

Fig. 2. Illustration of the effect of the parameter $A 1$ on the fitting procedure. The backscattering is expressed in arbitrary units (a.u.).

If the mixing height is initially estimated to be low (less than $700 \mathrm{~m}), A 1$ is chosen to be the backscattering intensity near the surface. Otherwise $A 1$ is defined as the mean backscattering intensity within the mixing layer. In such a case, a running mean is also used for smoothing the backscattering profile.

The effect of the choice of initial values (mainly $A 1$ ) on an actual profile fitting is shown in Fig. 2. This case displays a strong gradient near the surface, topped by a layer of nearly constant backscattering. Another strong gradient can be observed at the top of the convective mixing layer (ca. $2000 \mathrm{~m}$ ). If the value of $A 1$ is chosen erroneously based on the lowest strong gradient $(A 1=250)$, the resulting mixing height is too low, around $1000 \mathrm{~m}$. If the choice of $A 1$ is based on the second strong gradient corresponding to the mean backscattering in the layer below $2000 \mathrm{~m}(A 1=110)$, also the mixing height is determined correctly to be ca. $1600 \mathrm{~m}$.

Though the ceilometer can observe the atmosphere up to $7500 \mathrm{~m}$, it is not relevant to use the whole backscattering profile due to the strong white noise above $4000 \mathrm{~m}$. Therefore, the maximum height of the used profile was set at $4500 \mathrm{~m}$, but if the initial mixing height was lower than $1500 \mathrm{~m}$, only the first $3000 \mathrm{~m}$ of backscattering profile was used.

\subsection{Determination of the reference mixing height}

\subsubsection{Mixing height based on radiosoundings}

In convective situations, the $\mathrm{MH}$ was estimated from radiosounding temperature profiles using the Holzworthmethod (Holzworth, 1964, 1967). Its principle is to follow the dry adiabate starting at the surface up to its intersection with the actual temperature profile (Fig. 3). Thus, the method determines the maximum mixing height. This method depends strongly on the surface temperature (Seibert 


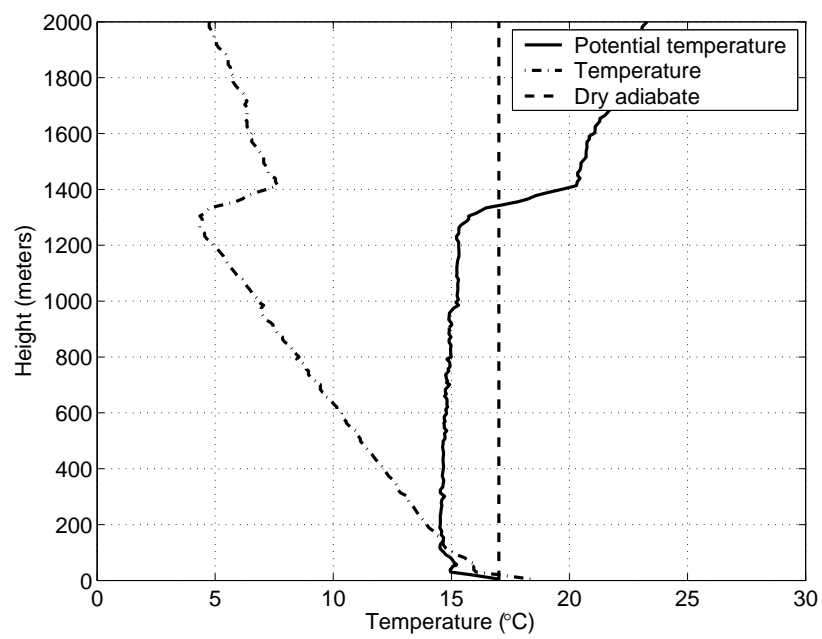

Fig. 3. Illustration of the Holzworth-method. Temperature profile at Vantaa, 29 May 2002 08:56 UTC.

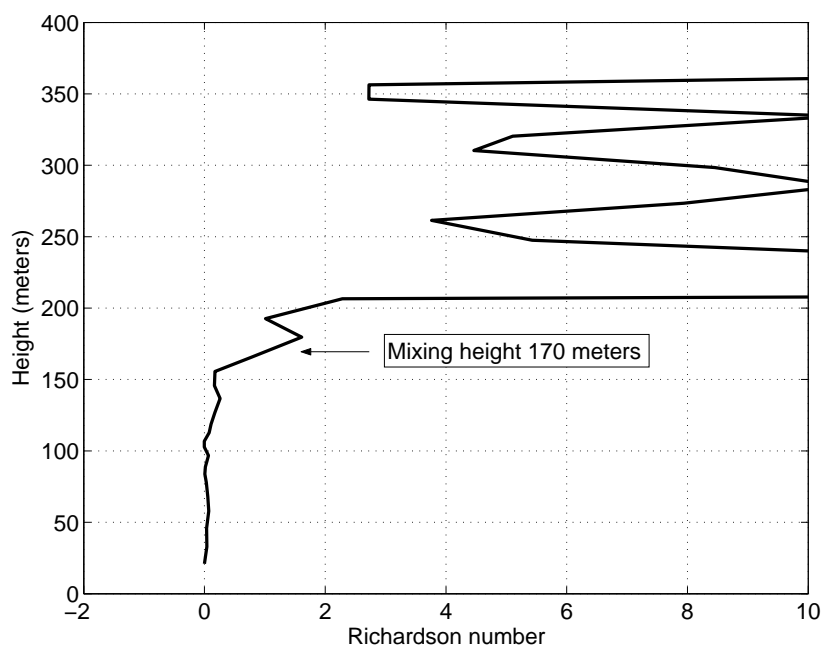

Fig. 4. An example of the Richardson number profile at Vantaa, 4 January 2002 07:17 UTC.

et al., 2000), and a high uncertainty may occur in a situation without a clear inversion at the convective boundary layer top.

In stable situations, the Richardson number $R i$ method has traditionally been used for determining the mixing height (Vogelezang and Holtslag, 1996). This method determines the equilibrium mixing height rather than the actual mixing height (Zilitinkevich and Baklanov, 2002) since the MH is identified as the level where $R i$ is equal or larger than a prefixed critical value. Thus, its accuracy is not very high, but the $\mathrm{MH}$ is not well defined either due to low and gradually decreasing turbulence intensity with height. In this project the Richardson number profile was determined by the formula of Joffre et al. (2001), which aims at smoothing out some of the inherent fluctuations (especially of wind) be-
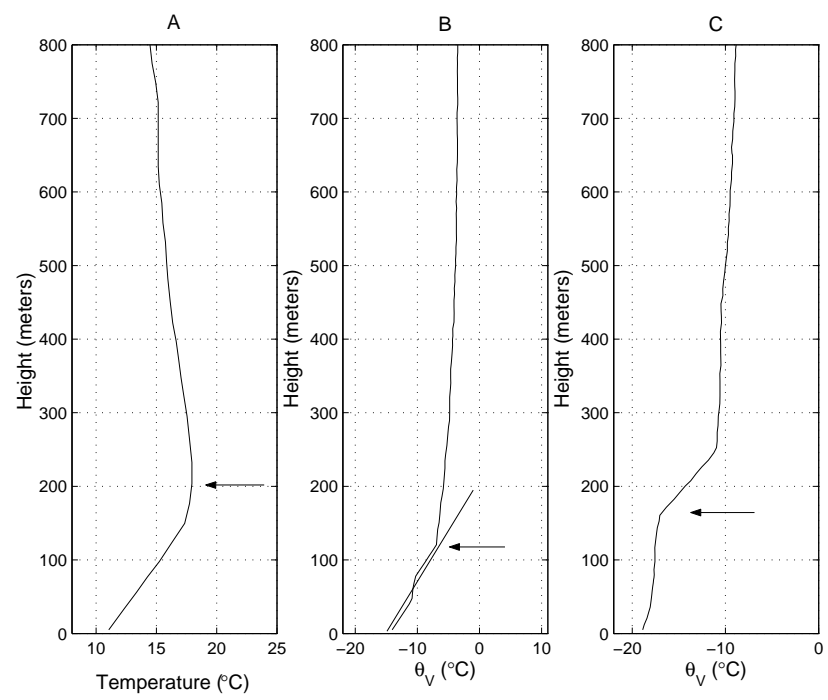

Fig. 5. Three ways for determining the reference mixing height from temperature profiles: (a) the height of the surface inversion (5 September 2002 06:06 UTC), (b) virtual potential temperature non-linearity (1 February 2002 07:02 UTC) and (c) strong winds - sharp virtual temperature increase above MH (2 January 2002 06:16 UTC).

tween adjacent layers:

$\operatorname{Ri}\left(z_{i+1}\right)=\frac{g}{T_{s}} \frac{\left(\theta_{i+2}-\theta_{i}\right)\left(z_{i+2}-z_{i}\right)}{\left(V_{i+2}-V_{i}\right)^{2}}$

where $T_{S}$ is the near-surface air temperature, $\theta_{i}$ the potential temperature and $V_{i}$ the wind speed at corresponding level $z_{i}$. The sub-index $i$ refers to the number of the layer of the profile.

Though the traditional value of the critical $R i$-number is 0.25 , there is evidence that it actually depends on various external conditions such as roughness and free flow stability or the Brunt-Väisälä frequency (Zilitinkevich and Baklanov, 2002). Several studies have found better fits with higher $R i$ values, in general in connection with a larger-scale approach (Joffre, 1981; Maryon and Best, 1992). The critical value used here was 1.0. Figure 4 displays an example of an observed $R i$-profile in Vantaa.

In the absence of wind profile data, the reference mixing height was determined in three different ways using the sole temperature profile. In method 1 , the $\mathrm{MH}$ was determined as the height of the surface inversion (Fig. 5a). In method 2, the MH was determined as the lowest level at which the virtual potential temperature begins to stray significantly from a linear profile (Wetzel, 1982; Fig. 5b). Under conditions of strong winds the potential temperature increases only slightly in the mixing layer (Zeman, 1979; Fig. 5c). This layer is capped by a quite shallow zone with a very sharp increase in temperature (Seibert et al., 1998). If the MH can be determined in more than one way, the average is used. 


\subsubsection{Mixing height estimated by the meteorological model MetPP-FMI}

The mixing height was also determined using the preprocessor model MetPP-FMI (Karppinen et al., 1997). The details of the mixing height scheme can be obtained from Karppinen et al. (1998) and Seibert et al. (2000). The evaluation of the boundary layer height is based upon routine radiosounding data. The model utilizes the midday (12:00 UTC) and midnight (00:00 UTC) soundings. Its main principles are that, under stable and neutral conditions, the MH is proportional to the friction velocity determined from the wind profile following the Monin-Obukhov similarity theory and to the heat flux integral (accumulated heat) as determined by the temperature difference between two subsequent profiles. Under unstable conditions, the MH is determined from the Tennekes (1973) model utilizing the measured temperature profiles and modelled stability parameters.

\subsubsection{Diagnostic methods for determining mixing height in stable situations}

In stable situations the mixing height is determined using three different diagnostic methods. The first method used is a heuristic model for the mixing height derived by Joffre and Kangas (2001):

$h=C_{s t} L_{N}^{3 / 4} L^{1 / 4}$

where $C_{s t}=7.71$ is an empirical constant, $L$ is the MoninObukhov length and $L_{N}=u_{*} / N$, where $u_{*}$ is the friction velocity and $N$ the Brunt-Väisälä frequency, which is determined from the radiosonde temperature profiles on a $200 \mathrm{~m}$ thick layer about $100 \mathrm{~m}$ above the mixing layer. This layer was chosen to represent the background stratification into which the PBL is embedded. The height of the layer was determined by the Richardson number method.

The Monin-Obukhov-length $L$ and the friction velocity $u_{*}$ are determined iteratively from the two lowest radiosounding observations (approximately 5 and $15 \mathrm{~m}$ ). It is clear that due to the known strong flings of the balloon in the first seconds of the sounding and to the sub-urban environment (heterogeneity), these estimates of $u_{*}$ are very uncertain and results should be considered with care.

The second method determines the MH based on the classical neutral formula involving the friction velocity $u_{*}$ and the Coriolis-parameter $f$ (Rossby and Montgomery, 1935)

$h=a \frac{u_{*}}{f}$

The proposed values for the empirical constant $a$ are scattered in the range of $a=0.05-0.3$. Here we have used the value $a=0.14$, corresponding roughly to the median of the values presented in the literature and also coinciding with the value presented by Arya (1981) based on sodar data.

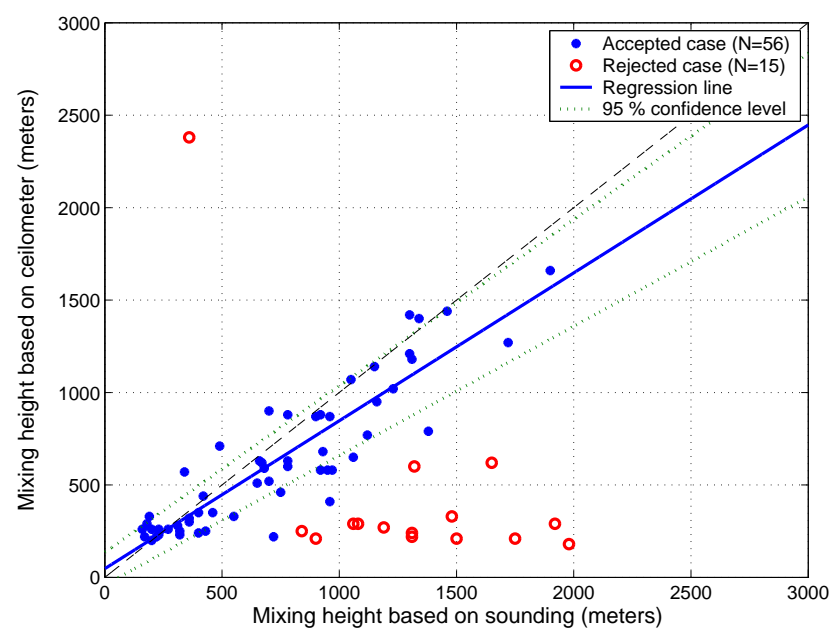

Fig. 6. Comparison between mixing heights determined by the ceilometer and radiosoundings (Holzworth method) in convective situations. Data points marked as hollow circles represent conditions with low backscattering signal.

The third method is a classical approximation for the height of the stable Ekman-layer (Zilitinkevich, 1972)

$h=B_{s} \sqrt{\frac{L u_{*}}{f}}$

We have used value $B_{s}=2$ for the empirical proportionality constant according to the original Zilintiekevich (1972) estimate.

\section{Results and discussion}

We present here the results of the comparison of ceilometer derived $\mathrm{MH}$ values with radiosounding estimates and various parametrisation scheme values. The analysis is performed separately for convective and stable conditions. This multiestimate approach is partly driven by both the fuzziness of the MH concept and the inherent limitations of each single model or method.

\subsection{Convective situations}

The comparison between MH values estimated by the ceilometer and those from radiosoundings is shown in Fig. 6. A total of 71 clear sky cases were analysed. Fifteen observations were tagged and rejected from the statistical analysis because they represented low backscattering signal conditions near the surface. A regression line was fitted to the remaining 56 observations (blue dots) yielding:

$h_{\text {ceilometer }}=(0.80 \pm 0.10) h_{\text {sounding }}+(47 \pm 89)$

The error margins of Eq. (6) correspond to 95\% confidence level of the regression coefficients. 


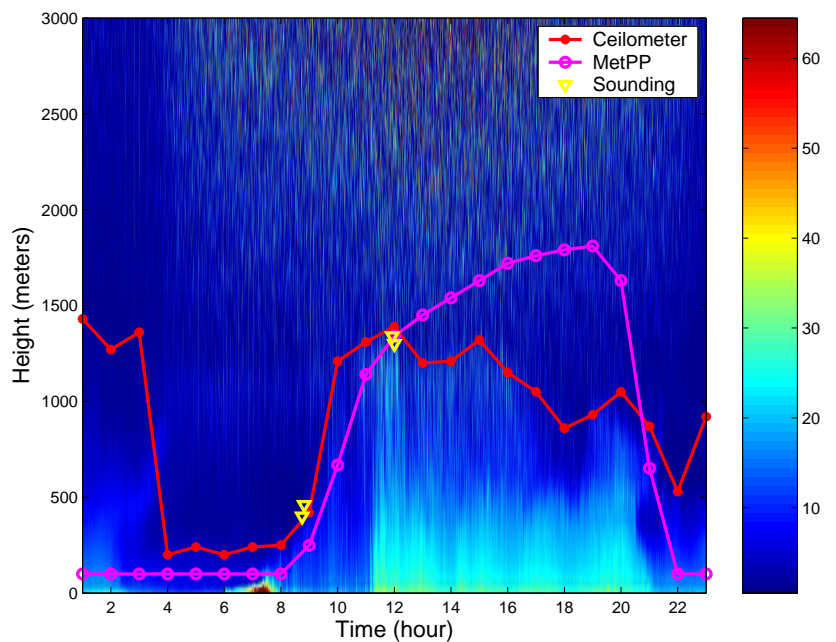

Fig. 7. A 24-h period of ceilometer echo intensity observations at Vantaa, 29 May 2002. The height of the MH determined by the ceilometer, the parcel method and the preprocessor (MetPP-FMI) are superimposed on the ceilometer raw echo data.

The correlation between the MH-estimates of these two methods is very significant (correlation coefficient $r=0.90$; correlation's $t$-score by Student's $t$-test $t=15.2$; confidence level $p>99.9 \%$ ). Thus, the mixing heights predicted by the ceilometer agree well with the mixing heights determined by the parcel method. However, this holds true only for the situations where the aerosol concentrations are high enough to provide reliable backscatter profiles, this method can not provide information on the $\mathrm{MH}$ if the backscatter signal near the surface is too low (red dots in Fig. 6).

On the average, the mixing height determined from radiosoundings is $8 \%$ higher than the one determined by the ceilometer. This difference is rather small in spite of the fact that these two methods differ in the physical definition of the mixing height. The Holzworth-method determines the maximum height of mixing from the potential temperature profile, while the ceilometer "feels" the height at which the aerosol profile reaches the edge of the mixing layer (with the implied assumption that aerosol are scarcer above the MH). Thus, at least qualitatively, this observed difference has a reasonable physical explanation.

An example of a full 24-h period of ceilometer observations is displayed in Fig. 7. It can be easily seen how turbulence gets stronger and the $\mathrm{MH}$ grows as the sun rises. On the other hand, the unrealistically high $\mathrm{MH}$ values during night time (01:00-03:00 a.m.) provide a good illustration of a potential problem using this method operationally. In this case the algorithm used for obtaining the initial values of the profile fitting procedure leads to erroneous result, as the night time residual aerosol layer is interpreted as the real mixed layer. Although this kind of misinterpretation can be easily avoided if other meteorological measurements are consid-

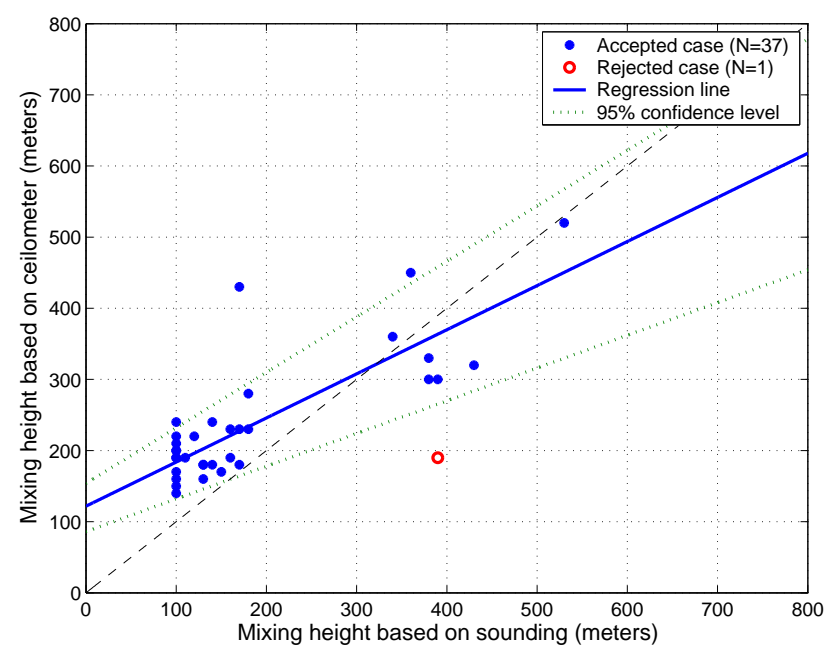

Fig. 8. Comparison between mixing heights determined by the ceilometer and radiosoundings ( $R i$-method) in stable situations (blue stars). The hollow circle corresponds to a case with low backscattering signal near the surface.

ered in the MH assessment, further work is still required to achieve a completely automatic algorithm for mixing height determination.

\subsection{Stable situations}

3.2.1 Comparison of mixing height estimated by the ceilometer and radiosoundings

The comparison between the MHs measured by the ceilometer and those estimated from radiosoundings (through the $R i$ method) is shown in Fig. 8. A total of 38 clear sky cases were analysed, of which only one was rejected from the statistical analysis due to low backscattering signal near the surface. The statistical analysis yielded the following regression line for the remaining 37 observations:

$h_{\text {ceilometer }}=(0.62 \pm 0.16) h_{\text {sounding }}+(120 \pm 34)$

The correlation between the two estimates is also in stable case very significant $(r=0.80 ; t=7.9 ; p>99.9 \%)$. On average, the mixing height determined from the sounding is $25 \%$ higher than the one determined by the ceilometer. Thus, the agreement is less than for unstable conditions but this was expected as the height of the MH is less well-defined under stable conditions without marked discontinuities in meteorological and probably aerosol profiles.

Figure 9 displays a period with a marked surface inversion that occurred on 2-3 January 2002. In case of a cloudy situation the MH determined by the ceilometer is zero. It can easily be seen that the absolute difference between the MHs determined by the ceilometer, from the soundings and the preprocessor models are not very large, only 100-200 m. The relative difference, however, is much larger since the $\mathrm{MH}$ is 
Table 2. Comparison of MH-values estimated by the ceilometer and three parametric methods to MH-values determined from radiosoundings using the Richardson number method.

\begin{tabular}{lclc}
\hline & Correlation coefficient & Regression line & Mean difference \\
\hline Ceilometer & 0.80 & $h_{\text {ceil }}=(0.62 \pm 0.16) h_{R i}+(121 \pm 34)$ & 73 \\
$C_{s t} L_{N}^{3 / 4} L^{1 / 4}$ & 0.28 & $h_{\mathrm{par} 1}=(0.33 \pm 0.46) h_{R i}+(106 \pm 103)$ & 100 \\
$a \frac{u_{*}}{f}$ & 0.06 & $h_{\mathrm{par} 2}=(0.09 \pm 0.59) h_{R i}+(206 \pm 133)$ & 140 \\
$B_{S} \sqrt{\frac{L u_{*}}{f}}$ & 0.53 & $h_{\mathrm{par} 3}=(4.1 \pm 2.8) h_{R i}-(327 \pm 623)$ & 350
\end{tabular}

shallow and at times the $\mathrm{MH}$ determined by the ceilometer is 3 times larger than the one determined by the preprocessor model.

On the basis of all the accepted stable situations, the lowest $\mathrm{MH}$ determined by the ceilometer is $140 \mathrm{~m}$, though estimates from radiosoundings and the preprocessor model indicate lower mixing heights. This would indicate that the ceilometer method cannot determine the mixing height in very stable situations, or that the mixing height in such situations is higher than soundings and the preprocessor model seem to indicate. This is linked to the unresolved issue of the simulation of strong stable situations in numerical weather prediction or dispersion models where standard schemes seem to indicate decaying turbulence with as a corollary weak surface fluxes and a shallow MH. On the other hand, scattered data seems to indicate that turbulence and surface fluxes can be sustained by non-local effects. Thus, none of the previous alternatives can be yet favoured.

\subsubsection{Comparison with diagnostic methods in stable situa-} tions

In stable situations, as an additional test, mixing height values estimated from the ceilometer and determined by three different parametric methods were compared to the mixing heights determined from radiosoundings by the Richardson number method (Table 2). The MH based on the Richardson number method acts also here as the reference value.

The mixing height determined by the ceilometer has clearly the best correlation with the mixing height determined by the Richardson number method. Also the mean difference between the MHs determined by these two methods is the smallest.

\section{Summary and conclusions}

When comparing mixing heights determined by a ceilometer from those by soundings, one must remember that these two approaches observe different characteristics. Soundings define the height up to which mixing can happen, while the ceilometer estimates the mixing height from the point of view of aerosol profiles. The latter assumes that aerosols are pri-

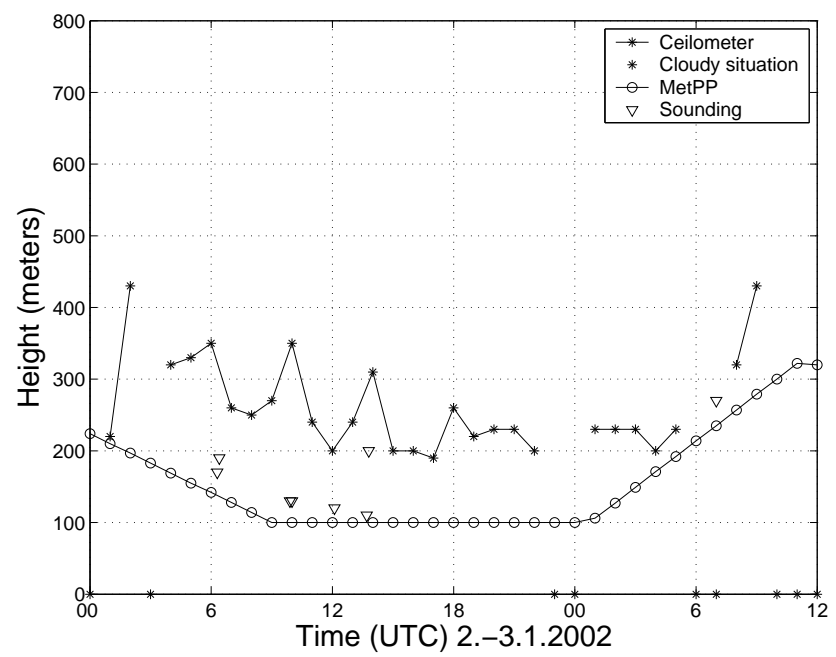

Fig. 9. Mixing height as determined by different methods or schemes during a surface temperature inversion (2-3 January 2002).

marily released from surface sources. On the other hand, aerosols can occur at elevated levels originating from distant sources or from the past history of the local PBL with a decoupling between the newly developing PBL and the fossil PBL.

Under convective situations, the mixing height determined by the ceilometer correlates well with the mixing height determined from radiosoundings with the parcel method (the correlation coefficient $r=0.90$ ). This can be considered as a reliable result due to the large number of observations. There are, however, some differences between these two methods (see Fig. 6) especially in cases of large mixing height when the Holzworth method yields larger mixing heights than the ceilometer. This can be explained, at least qualitatively, from the fact that these two methods define the mixing height physically in a different way. The Holzworth-method determines the maximum height of mixing from the potential temperature profile, while the ceilometer gives the height where the aerosol profiles indicate the edge of the mixed layer (with the implied assumption that aerosol are scarcer above the $\mathrm{MH})$. 
Under stable situations, there is a good connection between mixing heights determined by the ceilometer and those estimated from soundings with the $R i$-method. Even if there are fewer observations than in convective situations, this result can also be considered statistically reliable. In very stable situations, the mixing height determined by the ceilometer is higher than the one determined by parametric methods or estimated from soundings. Reliable conclusions, however, cannot be made because of only a few observations and the uncertainty with regards to turbulence structure and the $\mathrm{MH}$ under such situations.

Nevertheless, this study indicates that a ceilometer can be a suitable instrument for determining the convective mixing height. However, it cannot be used yet in a fully-automatic mode due to the need to cancel cloudy situations and the possibility of elevated aerosol layers outside the PBL. Compared to traditional, operational soundings, the advantage of the ceilometer is the possibility of obtaining $\mathrm{MH}$ information continuously with a very good vertical resolution.

Acknowledgements. The funding from the National Technology Agency of Finland (TEKES) Technology Programme: "FINE Particles - Technology, Environment and Health" is gratefully acknowledged.

\section{Edited by: A. Baklanov}

\section{References}

Angevine, W., A. White, B., and Avery, S. K.: Boundary layer depth and entrainment zone characterization with a boundarylayer profiler, Boundary-Layer Meteorol., 68, 375-385, 1994.

Arya, S. P. S.: Parameterizing the height of the stable atmospheric boundary layer, J. Appl. Meteorol., 20, 1192-1201, 1981.

Beyrich, F.: Mixing height estimation in the convective boundary layer using sodar data, Boundary-Layer Meteorol., 74, 1-18, 1995.

Beyrich, F.: Mixing height estimation from sodar data - a critical discussion, Atmos. Environ., 31, 3941-3953, 1997.

Cohn, S. A., and Angevine, W. M.: Boundary layer height and entrainment zone thickness measured by lidars and wind-profiling radars, J. Appl. Meteorol., 39, 1233-1247, 2000.

Emeis, S., Münkel, C., Vogt, S., Müller, W. J., and Schäfer, K.: Atmospheric boundary-layer structure from simultaneous SODAR, RASS and ceilometer measurements, Atmos. Environ., 38, 273286, 2004.

Emeis, S. and Türk, M.: Frequency distributions of the mixing height over an urban area from SODAR data, Meteorologische Zeitschrift, 13, 361-367, 2004.

Endlich, R. M., Ludwig, F., and Uthe, E. E.: An automated method for determining the mixing layer depth from lidar observations, Atmos. Environ., 13, 1051-1056, 1979.

Görsdorf, U. and Lehman, V.: Enhanced accuracy of RASSmeasured temperatures due to an improved range correction, J. Atmos. Oceanic Technol., 17, 406-416, 2000.

Hashmonay, R., Cohen, A., and Dayan, U.: Lidar observations of atmosphere boundary layer in Jerusalem, J. Appl. Meteorol., 30, 1228-1236, 1991.
Holzworth, C. G.: Estimates of mean maximum mixing depths in the contiguous United States, Mon. Wea. Rev., 92, 235-242, 1964.

Holzworth, C. G.: Mixing depths, wind speeds and air pollution potential for selected locations in the United States, J. Appl. Meteorol., 6, 1039-1044, 1967.

Joffre, S. M.: The Physics of the Mechanically-Driven Atmospheric Boundary Layer as an Example of Air-Sea Ice Interactions, University of Helsinki, Dept. of Meteorology, Report No. 20, 1981.

Joffre, S. M., Kangas, M., Heikinheimo, M., and Kitaigorodskii, S. A.: Variability of the stable and unstable atmospheric boundary layer height and its scales over a boreal forest, Boundary-Layer Meteorol., 99(3), 429-450, 2001.

Joffre, S. and Kangas, M.: Determination and scaling of the atmospheric boundary layer height under various stability conditions over a rough surface, edited by: Rotach, M., Fisher, B., and Piringer, M., COST Action 715 Workshop on Urban Boundary Layer Parameterisations (Zurich, 24-25 May 2001), Office for Official Publications of the European Communities, EUR 20355, 111-118, 2002.

Karppinen, A., Joffre, S., and Vaajama, P.: Boundary layer parametrization for Finnish regulatory dispersion models, Int. J. Environ. Pollut., 8, 557-564, 1997.

Karppinen, A., Kukkonen, J., Nordlund, G., Rantakrans, E., and Valkama, I.: A dispersion modelling system for urban air pollution, Finnish Meteorological Institute, Publications on Air Quality, 28, Helsinki, 1998.

Maryon, R. H. and Best, M. J.: NAME, ATMES and the boundary layer problem, UK Met. Office (APR) Turbulence and Diffusion Note, No. 204, 1992.

Melfi, S. H., Spinhirne, J. D., Chou, S.-H., and Palm, S. P.: Lidar observations of vertically organized convection in the planetary boundary layer over the ocean, J. Clim. Appl. Meteorol., 24, 806-821, 1985.

Menut, L., Flamant, C., Pelon, J., and Flamant, P. H.: Urban boundary-layer height determination from lidar measurements over the Paris area, Appl. Opt. LP, 38, 945-954, 1999.

Münkel, C. and Räsänen, J.: New optical concept for commercial lidar ceilometers scanning the boundary layer, Proceedings of SPIE, Vol. 5571, 364-374, 2004.

Rossby, C. G. and Montgomery, R. B.: The layer of frictional influence in wind and ocean currents, Pap. Phys. Oceanogr. Meteorol., 3(3), 1-101, 1935.

Seibert, P., Beyrich, F., Gryning, S.-E., Joffre, S., Rasmussen, A., and Tercier, Ph.: Mixing height determination for dispersion modelling, Report of Working Group 2, in: Harmonization in the Preprocessing of meteorological data for atmospheric dispersion models, COST Action 710, CEC Publication EUR 18195, pp. 145-265, 1998.

Seibert, P., Beyrich, F., Gryning, S.-E., Joffre, S., Rasmussen, A., and Tercier, $\mathrm{Ph} .:$ Review and Intercomparison of Operational Methods for the Determination of the Mixing Height, Atmos. Environ., 34(7), 1001-1027, 2000.

Sicard, M., Pérez, C., Comerón, A., Baldasano, J. M., Rocadenbosch, F.: Determination of the mixing layer height from regular lidar measurements in the Barcelona area, in: Remote Sensing of Clouds and the Atmosphere VIII, edited by: Schäfer, K. P., Comerón, C., Carleer, A. M. R., and Picard, R. H., Proceedings of SPIE, Bellingham, WA, USA, Vol. 5235, 505-516, 2004. 
Steyn, D. G., Baldi, M., and Hoff, R. M.: The detection of mixed layer depth and entrainment zone thickness from lidar backscatter profiles, J. Atmos. Ocean. Technol., 16, 953-959, 1999.

Tennekes, H.: A model for the dynamics of the inversion above a convective boundary layer, J. Atmos. Sci., 30, 550-567, 1973.

Vaisala Oyj: Ceilometer CT25K: User's guide, Vaisala Oyj, Vantaa, 2002.

Vogelezang, D. H. P. and Holtslag, A. A. M.: Evolution and model impacts of the alternative boundary layer formulations, Boundary-Layer Meteorol., 81, 245-269, 1996.

Wetzel, P. J.: Towards parameterization of the stable boundary layer, J. Appl. Meteorol., 21, 7-13, 1982.
White, A. B., Fairall, C. W., and Thomson, D. W.: Radar observations of humidity variability in and above the marine atmospheric boundary layer, J. Atmos. Oceanogr. Technol., 8, 539-558, 1991.

Zeman, O.: Parameterization of the dynamics of stable boundary layer and nocturnal jets, J. Atmos Sci., 36, 798-804, 1979.

Zilitinkevich, S. S.: On the determination of the height of the Ekman boundary layer, Boundary-Layer Meteorol., 3, 141-145, 1972.

Zilitinkevich, S. and Baklanov, A.: Calculation of the height of stable boundary layers in practical applications, Boundary-Layer Meteorol., 105(3), 389-409, 2002. 